\title{
Development of Efficient Technologies for Abatement of Nitrogen and Sulfur Oxides in Flues Gases of Coal Combustion
}

\author{
Vasily Murko \\ T.F. Gorbachev Kuzbass State \\ Technical University \\ Kemerovo, Russia \\ Nadezhda Shikina \\ Boreskov Institute of Catalysis \\ Novosibirsk, Russia
}

\author{
Veniamin Khyamyalyaynen \\ T.F. Gorbachev Kuzbass State \\ Technical University \\ Kemerovo, Russia
}

Zinfer Ismagilov

Institute of Coal Chemistry and

Material Science

T.F. Gorbachev Kuzbass State

Technical University

Boreskov Institute of Catalysis

Kemerovo, Russia

\author{
Ekaterina Mikhaylova \\ Institute of Coal Chemistry and \\ Material Science \\ T.F. Gorbachev Kuzbass State \\ Technical University \\ Kemerovo, Russia \\ e_s_mihaylova@mail.ru
}

\begin{abstract}
Results of development of technologies for purification of coal-fired power plants from nitrogen and sulfur oxides in the frame of Russian-Chinese Project No. 14.583.21.0004 are presented.
\end{abstract}

Keywords - coalcombustion, nitrogen oxides, sulfur oxides, sulfur-absorbingreagents

\section{Description of the problem:}

At present removal of nitrogen and sulfur oxides from flue gases of power plants is considered an important scientifictechnical problem, solution of which is connected with an environmentally safe generation of thermal and electric energy. In many countries, contemporary standards of the design of newly created coal-fired power plants require building treatment facilities for removal of nitrogen and sulfur oxides, and in some countries mercury, from flue gases. Existing domestic coal-fired power plants recover only some part of ash (on filters) from all anthropogenic contaminants. All other toxic compounds, such as $\mathrm{NO}_{\mathrm{x}}, \mathrm{SO}_{2}$, and $\mathrm{SO}_{3}$ are emitted into the atmosphere without any treatment. That is why a comprehensive approach to the solution of this problem is required, including both incremental modernization of the equipment and implementation of specialized solutions and technologies for the flue gas treatment (deNOx and desulfurization systems at the stages of fuel preparation and gas purification with the use of sorption and catalytic methods, removal of heavy metals, etc.).

In the frame of the realization of Russian-Chinese Project \#14.583.21.0004 an original comprehensive technology for efficient purification of flue gases of electric and thrmal coal-fired power plants from nitrogen and sulfur oxides was created, which will allow a decrease of the technogenic impact of energy producing enterprises on the environment. This technology was realized in a specially constructed experimental test bench.
The technology, used equipment, results of tests

The technology of purification of coal-fired power plants from toxic compounds involves the combination of various methods:

- lowering of the content of sulfur oxides formed upon the combustion of sulfur-containing fuel by the introduction of sulfur-absorbing reagents (SAR) into the combustion zone;

- a decrease of the content of nitrogen oxides in flue gases by the use of catalytic treatment methods.

The use of sulfur-absorbing reagents is based on the introduction of specially prepared SAR either into the composition of a coal fuel or into the combustion zone. Thus sulfur of fuel or sulfur compounds formed during combustion are transformed into solid compounds that are transferred to ash-and-slag wastes or captured in the composition of fly ash by the dust treatment system of the plant.

Figure 1 presents the site for preparation of coal fuel (including water-coal slurry fuel) and SAR in the composition of the test bench created in the frame of the project. 


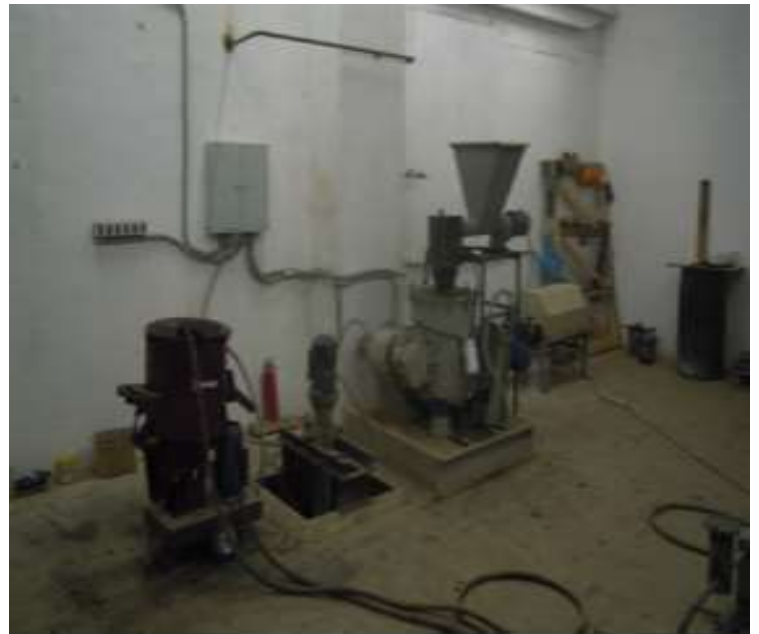

Figure 1 - The site for preparation of coal fuel and SAR

As the main technology of the fuel preparation for the combustion, the technology of water-coal slurry fuel (WCF) was used [1-3]. The water-coal slurry fuel containing SAR was prepared from the mixture of the filtercake of "Barzas Association", technical water and a plasticizing additive. For the use as a sulfur absorbing additive, a dolomite mineral $\left[(\mathrm{CaMg}) \mathrm{CO}_{3}\right]$ was used, capable of fast and reliable sulfur capture. The water suspension of this SAR was prepared in the shredding installation of periodic performance by wet milling of crushed dolomite marble stone. The SAR consumption was calculated from the sulfur content in fuel and the stoichiometric ratio required for the binding of fuel sulfur, including sulfate sulfur:

$$
\mathrm{CaMg}\left(\mathrm{CO}_{3}\right)_{2}+2 \mathrm{SO}_{2} \Rightarrow \mathrm{CaCO}_{3}+\mathrm{SO}_{2}+\mathrm{MgCO}_{3}+\mathrm{SO}_{2} \Rightarrow
$$

$\mathrm{CaSO}_{3}+\mathrm{CO}_{2}+\mathrm{MgSO}_{3}+\mathrm{CO}_{2}$.

The prepared water-coal fuel was fed into the furnace by compressed air supplied into an air-mechanical injector. The rate of fuel supplied into the furnace was regulated in such way as to provide the heat generation of $0.63 \mathrm{MW}$ at the complete combustion of fuel with a lower calorific value of $2681-3167 \mathrm{kcal} / \mathrm{kg}$. The temperature in the furnace was $1000-1100^{\circ} \mathrm{C}$. The site of coal fuel combustion is shown in Fig. 2.

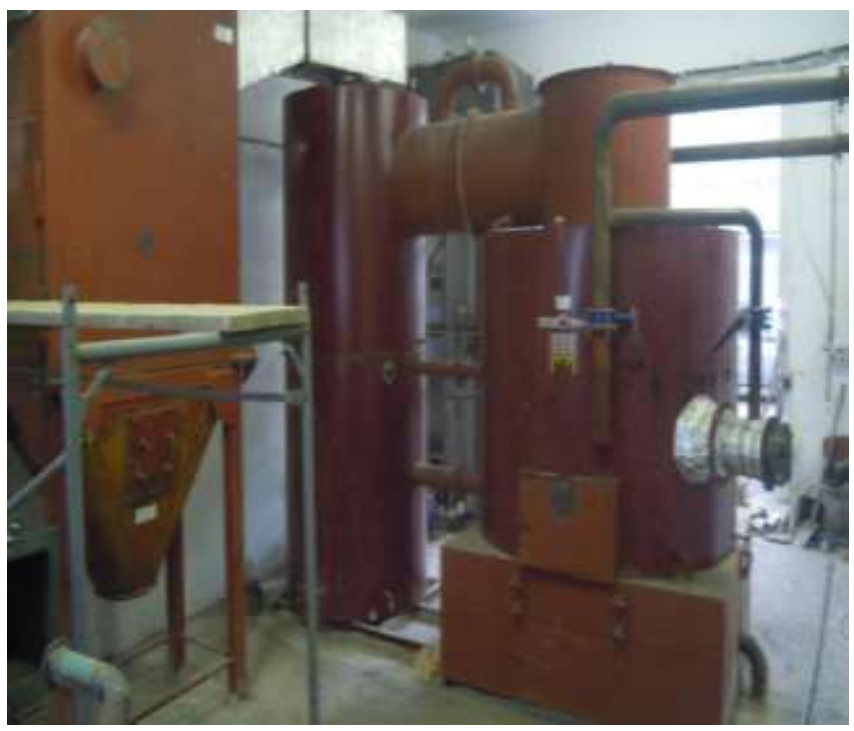

Figure 2 - The site of coal fuel combustion.
Table 1 presents the results of water-coal combustion with the use of SAR. To increase the sulfur content in the fuel the addition of technical carbon was used.

Table 1 - Sulfur oxides in gas emissions from the combustion of suspended coal fuels

\begin{tabular}{|c|c|c|}
\hline Type of fuel & $\begin{array}{c}\text { Content of } \\
\text { sulfur oxides in } \\
\text { flue gases,mg / } \\
\text { nm3 }\end{array}$ & $\begin{array}{l}\text { Reduction of } \\
\text { harmful } \\
\text { emissions into } \\
\text { the } \\
\text { atmosphere, } \%\end{array}$ \\
\hline 1 & 2 & 3 \\
\hline \multicolumn{3}{|c|}{ Filter-cake "Barzas Association" } \\
\hline $\begin{array}{l}\text { WCF }(\mathrm{Cf} .=59,5 \%- \\
\text { filter-cake }+0,3 \% \text { type } \\
\text { T) }\end{array}$ & 250 & 0 \\
\hline $\begin{array}{l}\text { WCF }(\mathrm{Cf}=58,0 \% \\
\text { filter-cake }+0,3 \% \text { typeT } \\
+1,06 \% \mathrm{CaMg}\left(\mathrm{CO}_{3}\right)_{2}\end{array}$ & 76 & 70,5 \\
\hline $\begin{array}{l}\text { WCF }(\mathrm{Cf}=59,5 \% \\
\text { filter-cake }+0,3 \% \text { type } \\
\text { T) }+1,06 \% \mathrm{CaMg}\left(\mathrm{CO}_{3}\right)_{2}\end{array}$ & 77 & 70,2 \\
\hline \multicolumn{3}{|c|}{\begin{tabular}{|l} 
Filter-cake "Barzas Association"+ technical coa \\
\end{tabular}} \\
\hline $\begin{array}{l}\text { WCF }(\text { Cf. }=32,0 \% \\
\text { filter-cake }+20,7 \% \\
\text { technical carbon }+ \\
0,3 \% \text { type } \mathrm{T})\end{array}$ & 830 & 0 \\
\hline $\begin{array}{l}\text { WCF }(\mathrm{Cf}=29,5 \% \\
\text { filter-cake }+19,6 \% \\
\text { technical carbon }+ \\
0,3 \% \text { type } \mathrm{T}+3,8 \% \\
\mathrm{CaMg}\left(\mathrm{CO}_{3}\right)_{2}\end{array}$ & 158 & 81 \\
\hline $\begin{array}{l}\text { WCF }(\mathrm{Cf}=32,0 \% \\
\text { filter-cake }+20,7 \% \\
\text { technical carbon }+ \\
0,3 \% \text { type } \mathrm{T}+3.8 \% \\
\mathrm{CaMg}\left(\mathrm{CO}_{3}\right)_{2}\end{array}$ & 153 & 82,3 \\
\hline
\end{tabular}

As can be seen from the results of the combustion tests, the reduction of harmful emissions into the atmosphere formed upon the fuel combustion, achieved by the use of sulfur absorbing reagents in the combustion zone is equal to $70.2-82.3 \%$.

Then the flue gases were directed to the catalytic treatment system.

The catalytic purification of flue gases from nitrogen oxides is conducted most efficiently by the use of monolithic catalysts working at high space velocities and low contact times. Monolithic catalysts are widely used in the gas treatment practice of Western countries and Japan. The supports used for the preparation of these catalysts are $\mathrm{Al}_{2} \mathrm{O}_{3}$ [4-5], $\mathrm{TiO}_{2}$ [6-8], $\mathrm{ZrO}_{2}$ and their mixtures, zeolites, [9-14], prepared as honeycomb monoliths.

The existing methods of catalytic purification of flue gases from nitrogen oxides are based on $\mathrm{NO}_{\mathrm{x}}$ reduction by the following reducing agents: ammonia, hydrocarbons, carbon monoxide, etc. [15-17]. The literature analysis shows that the most promising catalytic systems are individual or mixed transition metal oxides. In multi-component systems, 
one metal usually modifies the catalytic properties of another one as a result of the mutual electronic and structural effects.

For the tests of gas purification from $\mathrm{NO}_{\mathrm{x}}$ in the pilot flue gas cleaning unit, experimental samples of monolithic $\mathrm{Fe}-\mathrm{Cr}-\mathrm{Zn} / \mathrm{Al}_{2} \mathrm{O}_{3}$ catalysts were prepared.

The catalytic flue gas cleaning unit is shown in Fig. 3.

The treated gas before the supply to the catalytic reactor (Fig. 4) is heated to the temperature $350-400^{\circ} \mathrm{C}$ by a flow heater. The design of the catalytic reactor includes a thermocouple well with a chromel-alumel thermocouple installed in the center of the catalyst bed for the measurement of the gas temperature. At the inlet of the reactor, the gas is mixed with ammonia. For the supply and measurement of the ammonia flow, a standard rotameter is used. Ammonia supply was regulated manually by the rotameter. The amount of the supplied ammonia depends on the $\mathrm{NO}_{\mathrm{x}}$ content in the treated gas $\left(\mathrm{NH}_{3} / \mathrm{NO}_{\mathrm{x}}=1 / 1\right)$. For the measurement of the concentration of nitrogen oxides in gas flows and evaluation of the efficiency of the flue gas cleaning unit, three gas sampling points were provided: at the reactor inlet, in the reactor after ammonia supply and at the reactor outlet. The analysis of the treated flue gas was performed using a quadrupole mass analyzer QMS 300 permitting the measurement of low concentrations of pollutants [18-19].

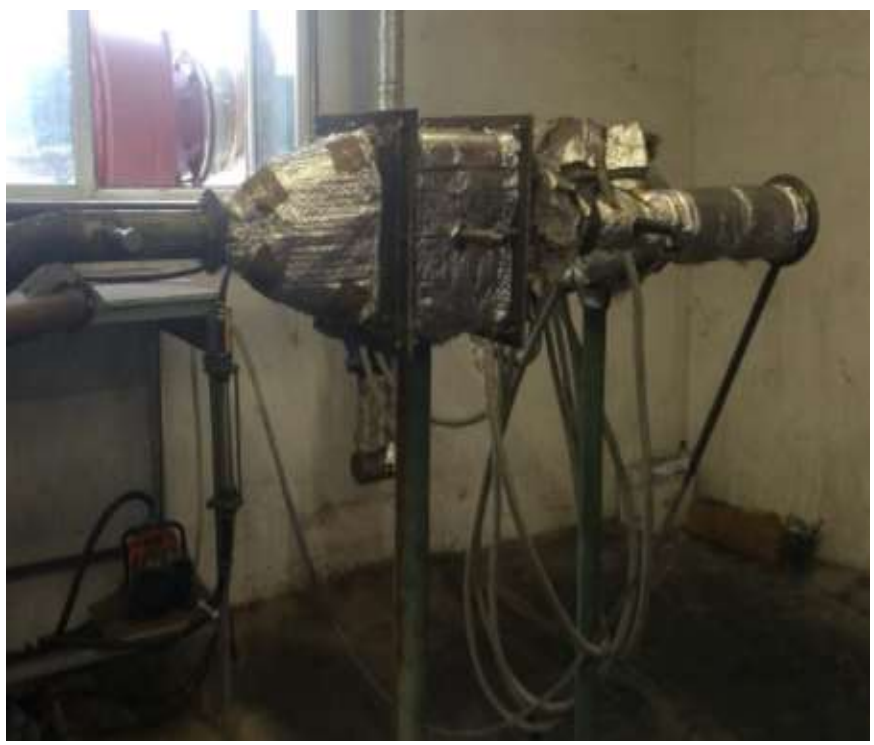

Figure 3 - Catalytic flue gas cleaning unit

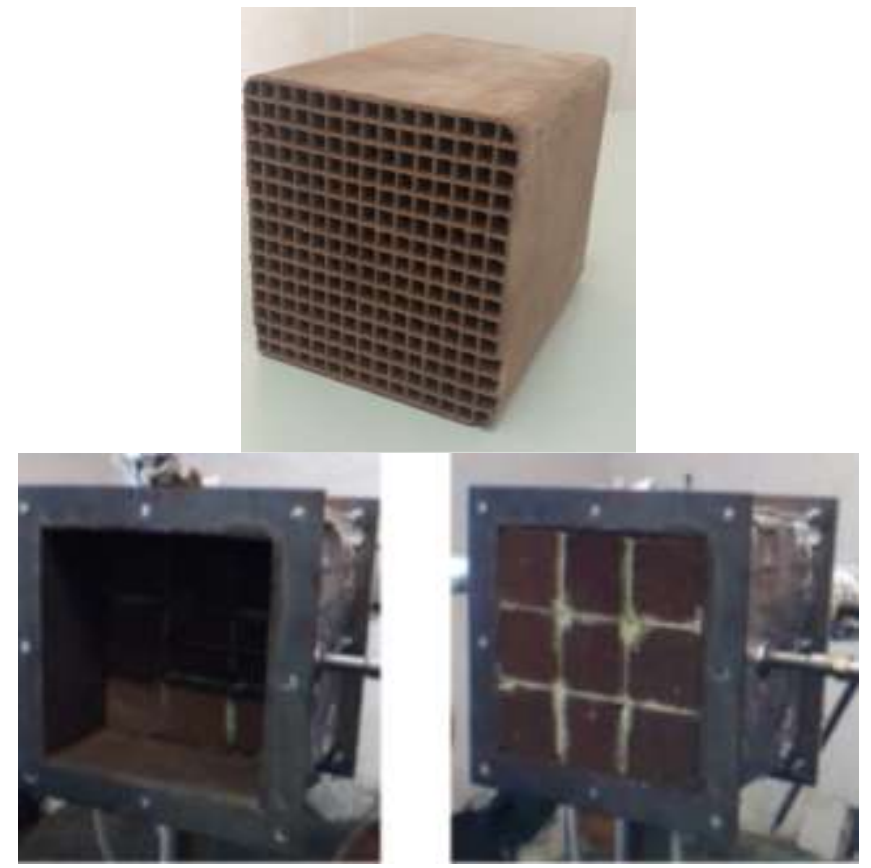

Figure 4 - Catalytic reactor filled with catalyst monoliths

The results of the tests in the experimental test bench showed that the efficiency of flue gas purification from pollutants attained the following values:

- removal of sulfur oxides using dolomite as a SAR was equal to $70.2-82.3 \%$;

- removal of nitrogen oxides using the catalytic treatment attained $94 \%$.

Thus, the results of the work allow concluding that the technology of abatement of pollutants formed in the flue gases of coal-fired power plants developed under the project is sufficiently efficient and can be recommended for the implementation at the existing and designed energygenerating enterprises.

\section{References}

[1] Murko, V.I. Fedyaev, H.L. Aynetdinov, M.P. Baranova. Enviromentally clean techology of fine waste coal utilization//17th International Coal Preparation Congress. 16 October 2013, Istanbul, Turkey, p. 679-682.

[2] V.I.Murko, V.I.Karpenok, Y.A.Senchurova. Results of study of sulfur oxide reduction during combustion of coalwater slurry fuel through use of sulfur capturing agents matec web of conferences, 2016, vol.72, p.1.

[3] V.I.Murko, V.I. Karpenok, V.I.Fedyaev, S.A.Silyutin. The development of a technological complex for utilization of fine waste coal PP "Tugnuyskaya". In XVIII International Coal Preparation Congress Conference Proceedings, 2016, p. 339-343.

[4] S. Parres-Esclapez, M.J. Illan-Gomez, C. SalinasMartinez de Licea, A. Bueno-Lopez. On the importance of the catalyst redox properties in the $\mathrm{N}_{2} \mathrm{O}$ decomposition over alumina and ceria supported $\mathrm{Ph}, \mathrm{Pd}$ and $\mathrm{Pt}$. Applied Catalysis B: Environmental,2010, vol. 96, p. 370-378.

[5] M. Shimokawabe, A. Kuwana, S. Oku et.al. SCR of NO by $\mathrm{DME}$ over $\mathrm{Al}_{2} \mathrm{O}_{3}$ based catalysts: Influence of noble metals and $\mathrm{Ba}$ additive on low-temperature activity. Catalysis Today, 2011, vol.164, p. 480-483. 
[6] Z.H. Zheng, H. Tong, Z.Q. Tong et.al. Catalytic reduction of $\mathrm{NO}$ over $\mathrm{Mn}-\mathrm{V}-\mathrm{Ce}-\mathrm{TiO} 2$ catalyst at low reaction temperature/ Journal of Fuel Chemistry and Technology, 2010, vol. 38, No 3, p. 343-351.

[7] Z.X. Zhang. Low-temperature SCR of NO with propylene in excess oxygen over the $\mathrm{Pt} / \mathrm{TiO} 2$ catalyst. Catalysis Communications, 2009, vol. 10, p. 1330-1333.

[8] B. Thirupathi, P.G. Smirniotis Nickel-doped $\mathrm{Mn} / \mathrm{TiO} 2$ as a efficient catalyst for the lowtemperature SCR of NO with NH3: Catalytic evaluation and characterizations/ Journal of Catalysis, 2012, vol.288, p. 74-83.

[9] J.M. Fedeyko, B. Chen. Mechanistic study of the low temperature activity of transition metal exchanged zeolite SCR catalysts. Catalysis Today, 2010, vol. 151, p. 231-236. [10] Patent RF 2510763, Int. Cl. B 01 D 53/56, B 01 D 53/94, B $01 \mathrm{~J} 20 / 00$. Method and catalyst for removal of nitrogen oxides from exhaust gases method and catalyst for removal of nitrogen oxides from exhaust gases. Tegersen Joakim Rejmer (Denmark), Applicant Haldor Topsoe (Denmark), Application No 2011127886/05, priority date 27.11.2009; publ. 10.04.2014.

[11] Patent RF 2506999, Int. Cl. B 01 J 29/46, B 01 J 37/12, B $01 \mathrm{~J}$ 37/16. Method for the production of an SCR-active zeolite catalyst, and SCR-active zeolite catalyst. Münch Jörg, Werner (Germany), Dotzel Ralf (Germany), Applicant JOHNSON MATTHEY CATALYSTS (Germany), Application No 2012110196/04, 21.08.2010; priority date 05.09.2009, publ. 20.02.2014.

[12] J.H. Li, H.Z. Chang, L. Ma et.al. Low-temperature selective catalytic reduction of NOx with NH3 over metal oxide and zeolite catalysts-A review. Catalysis Today, 2011, vol. 175, p. 147-156.

[13] Z.R.Ismagilov, R.A.Shkrabina, L.T.Tsikoza S.A.Yashnik, et al. The Stability of Monolith CuZSM-5 Catalysts for the Selective Reduction of Nitrogen Oxides with Hydrocarbons: I. Synthesis and Characterization of
Bulk CuZSM-5 Catalysts, Kinetics and Catalysis, 2001, vol.42, Issue 6, p. 847-853.

[14] Z.R.Ismagilov, R.A.Shkrabina, L.T.Tsikoza S.A.Yashnik, et al. The Stability of Monolith CuZSM-5 Catalysts for the Selective Reduction of Nitrogen Oxides with Hydrocarbons: II. Synthesis and Characterization of Bulk Cu $\left(80 \%\right.$ ZSM-5 + 20\% $\left.\mathrm{Al}_{2} \mathrm{O}_{3}\right)$ Catalysts, Kinetics and Catalysis, 2001, Vol.42, Issue 6, p. 854-856.

[15] Z.R. Ismagilov, O.Y. Podyacheva, O.P. Solonenko. Application of plasma spraying in the preparation of metalsupported catalysts. 2nd International Memorial G K Boreskov Conference on the Catalysis on the Eve of the XXI-Century Science and Engineering, JUL 07-11, 1997.

[16] Z.R. Ismagilov, R.A. Shkrabina, S.A. Yashnik. Supported honeycomb monolith catalysts for hightemperature ammonia decomposition and $\mathrm{H} 2 \mathrm{~S}$ removal. 1st International Conference on Structured Catalysts and Reactors (ICOSCAR-1), Catalysis today, 2014, vol.69, p.351-356.

[17] Z.R. Ismagilov, S.A. Yashnik, A.N. Startsev. Deep desulphurization of diesel fuels on bifunctional monolithic nanostructured Pt-zeolite catalysts. Catalysis today, 2009, vol. 144 , p. $235-250$

[18] N.V. Shikina, S.R. Khairulin, S.A. Yashnik, T.N. Teryaeva, Z.R. Ismagilov. Direct Catalytic Reduction of $\mathrm{SO} 2$ by $\mathrm{CH} 4$ over Fe-Mn Catalysts Prepared by Granulation of Ferromanganese Nodules. Eurasian ChemicoTecnological Journal, 2015, Vol. 17, p. 129-136.

[19] N.V. Shikina, S.R. Khairulin, N.A. Rudina, T.N. Teryaeva, E.S. Mikhaylova, Z.R. Ismagilov. Investigation of the Sorption Properties of Ore Materials for the Removal of Sulfur Dioxide from Exhaust Flue Gases of Power Plants. Eurasian Chemico-Tecnological Journal, 2015, vol.17, p. 137-143. 